\title{
BMJ Open Is there an ethnic variation in the epidemiology of gonorrhoea? A retrospective population-based study from northern Israel over 15 years between 2001 and 2015
}

\author{
Khalaf Kridin, ${ }^{1}$ Rami Grifat, ${ }^{2,3}$ Mogher Khamaisi ${ }^{4}$
}

To cite: Kridin $\mathrm{K}$, Grifat $\mathrm{R}$, Khamaisi $M$. Is there an ethnic variation in the epidemiology of gonorrhoea? A retrospective populationbased study from northern Israel over 15 years between 2001 and 2015. BMJ Open 2017;7:e014265.

doi:10.1136/bmjopen-2016014265

- Prepublication history for this paper is available online. To view these files please visit the journal online (http://dx.doi.org/10.1136/ bmjopen-2016-014265).

KK and RG contributed equally to this paper.

Received 13 September 2016 Revised 21 January 2017 Accepted 1 February 2017

CrossMark

For numbered affiliations see end of article.

Correspondence to Dr Khalaf Kridin; dr_kridin@hotmail.com

\section{ABSTRACT}

Objective: To investigate the trends in the incidence of gonorrhoea through an extended period of time and to compare the epidemiology of gonorrhoea infection between 2 distinct ethnic groups (Jews and Arabs).

Design: A retrospective population-based cohort study was conducted on all consecutive patients diagnosed with gonorrhoea through the years 2001-2015.

Setting: National Department of Epidemiology of the Ministry of Health, Haifa District, Israel.

Participants: A total of 837 reports on gonorrhoea were received, derived from $779(93.1 \%)$ male and 58 (6.9\%) female patients. Approximately 1 million people reside in the Haifa region.

Primary and secondary outcome measures: We examined the incidence rate of gonorrhoea among residents of Haifa District, northern Israel from 2001 to 2015, by reviewing archives of the Department of Epidemiology, Israeli Ministry of Health. Notified cases were stratified by age, gender and ethnicity.

Results: The overall gonorrhoea incidence was 6.4 cases per 100000 population per year. The annual incidence rate dropped from 20.5 per 100000 population in 2001 to a period of 2.2 cases per 100000 population in 2005, showing a >9-fold decline. This was followed by a relatively steady increase of incidence of 2.5-4.5 per 100000 population from 2006 to 2015 . Men were predominantly more affected than women, with a 13.4fold higher incidence rate. The most affected age group was residents between 25 and 34 years old. The estimated rate among Jews was 2.5 -fold higher relative to Arabs. Only $1.3 \%$ recurrent episodes of gonorrhoea were reported. The prevalence of HIV positivity among patients with gonorrhoea is significantly higher than that of the general population (500.0 vs 88.1 cases per 100000 population, respectively, $p<0.001)$.

Conclusions: Gonorrhoea incidence rate decreased dramatically until 2005 , with no substantial subsequent fluctuations. The infection is much more prevalent among patients of Jewish ethnicity, possibly due to riskier sex practices.

\section{Strengths and limitations of this study}

- The study sheds light on novel and remarkable differences in the epidemiology of gonorrhoea among different ethnic populations within the same geographic region.

- The study uses data collected over an extensive period of time (from 2001 to 2015).

- The validity of notifications is very high, as Israeli law mandates reporting of gonorrhoea cases, both from physicians and from microbiological laboratories.

- The retrospective design of the study itself is a limitation.

- Data are from a relatively small region populated with no more than one million inhabitants. This may weaken the external validity and generalisability of our observations.

- There was no elucidation of the precise method of gonorrhoea transmission or the sexual orientation of cases, which reduced the potential to focus on the exact causes and target populations. Furthermore, we could not examine trends of the infection among men who have sex with men, which is the group associated with the majority of outbreaks of gonorrhoea infection in industrialised countries.

\section{INTRODUCTION}

Gonorrhoea has affected humans for centuries and remains common, with an estimated 88 million cases occurring annually worldwide. ${ }^{1}$ It is the second most commonly reported notifiable sexually transmitted disease (STD) in Israel. ${ }^{2}$ Infections due to Neisseria gonorrhoeae are a remarkable aetiology of pelvic inflammatory disease, which can lead to several complications in women such as tubal infertility, ectopic pregnancy and chronic pelvic pain. In men, the majority of infections cause urethritis with painful 
urination and, less commonly, epididymitis or disseminated gonococcal infection. Epidemiological and biological studies demonstrate that gonococcal infections raise the transmission of HIV infection by $3-5$-fold. ${ }^{3-5}$ Although an individual's sexual practice might increase the susceptibility to gonorrhoea, social determinants of health, such as socioeconomic status, may contribute to the burden of gonorrhoea in a community. ${ }^{6}$

Earlier studies monitoring gonorrhoea in Israel reported a significant decline in the incidence rate starting in the early 1970 s, resulting in $<1$ case per 100000 population between 1993 and 1997. There was a reversal in this trend seen from 1998 to 2002, as the annual rate increased until reaching peak incidence in 2002; however, since then, incidence rate again is declining. ${ }^{2}$ Recent reports from several European Union (EU) countries have revealed increases in gonorrhoea incidence, particularly in populations with higher frequency of spread of STD, such as men who have sex with men (MSM) and young heterosexual individuals of both genders. ${ }^{7-9}$

Gonorrhoea disproportionately affects racial and ethnic groups, with higher rates reported among certain minorities. ${ }^{10}$ However, not much is known about differences in the epidemiology of gonorrhoea between the Jewish and Arab populations in Israel.

In this paper, we examined the epidemiology of gonorrhoea in the Haifa District over a period of 15 years in order to clarify the differences between Jews and Arabs. Moreover, we examined the proportion of HIV positivity among patients with confirmed comorbid gonorrhoea compared with those with gonorrhoea alone within the general population, estimated the rate of reinfections, and assessed the seasonal pattern of infection.

\section{METHODS}

Gonorrhoea is a notifiable disease in Israel. The first law in Israel mandating reporting of venereal diseases, contact tracing and treatment of cases and their contacts came into force in 1940 by the British mandate. Notification was performed by primary care physicians and hospitals or by microbiology laboratories throughout the country to the corresponding public health districts. The information was then collated at the Department of Epidemiology of the Ministry of Health of Israel. This passive surveillance system established in the early 1950s and still in use today provides long-term assessment of the trends in disease incidence in Israel. As in other venereal disease, contact tracing and recommendation for treatment of cases and their contacts is conducted by an epidemiological nurse from the Ministry of Health, who contacts all cases by telephone and performs an epidemiological investigation.

The definition of gonorrhoea was grounded on satisfying the laboratory criteria alongside corresponding suggestive clinical presentation. The laboratory criteria are as follows: (1) $N$. gonorrhoeae has been isolated from a clinical specimen using bacterial culture, (2) N. gonorrhoeae nucleic acid has been demonstrated in a clinical specimen, and/or (3) N. gonorrhoeae Gram-negative Diplococci have been identified in a urethral smear from a man reporting on dysuria and urethral discharge. In the past few years, nucleic acid amplification tests using PCR are more widely implemented in microbiological laboratories, especially when examining clinical specimens from female patients.

In this retrospective population-based cohort study, we calculated incidence using all reported gonorrhoea cases per 100000 population (total, female or male, age group-specific). Population data within Haifa District was extracted from Israel's Central Bureau of Statistics (http://www.cbs.gov.il). According to the 2008 census of the Central Bureau of Statistics, 650000 (75.7\%) Jews and $211000(24.3 \%)$ Arabs reside within the Haifa District.

Our way to avoid information bias that may have originated from the cross-sectional design of the study was to adopt a standardised and even method of notification; all reports included in the analysis were based on a uniform and validated forms created by the Ministry of Health.

\section{Data analysis}

We examined cases of gonorrhoea infection occurring between 2001 and 2015 that were reported to the local Haifa District Department of Health. Cases were included if either a correct physical address or postal code for Haifa District was available. We excluded cases in which the address was unknown or did not belong to Haifa District. We also excluded cases if there had been a repeat test within an interval of $<90$ days. We then stratified the number of cases by year, age group, gender, and Jewish or Arab ethnicity. Trends over time were tested by Poisson regression. The seasonal incidence rate for summer (April to September) and winter (October to March) were calculated on the basis of the ratio between the number of cases during the 6-month period under study and the average monthly number of inhabitants in each year.

The $\chi^{2}$ analysis was used to compare rates. relative risks (RRs) and 95\% CIs were calculated. All calculations were performed using Stata V.11.0, StataCorp LP, College Station, Texas, USA.

\section{RESULTS \\ Overall trends}

In the study period, 837 reports on gonorrhoea were received, corresponding to an overall annual incidence rate of 6.4 (95\% CI 6.0 to 6.8$)$ cases per 100000 population. One hundred and seventy-eight $(21.3 \%)$ cases were reported by clinicians from STD clinics, dermatology and gynaecology departments. The remainder of the notifications were provided by microbiological laboratories. Twenty-four anonymous notifications were excluded from 
all analyses. A significant overall decrease was observed throughout the study period ( $p_{\text {trend }}=0.023$ ). There was a steep decline in the incidence rates over the first 5 years of the study $\left(p_{\text {trend }}=0.014\right)$, followed by a relatively steady increase of incidence from 2006 to 2015, interspersed with several peaks of decline $\left(p_{\text {trend }}=0.590\right)$. The incidence rate of gonorrhoea dropped from 20.5 per 100000 population in 2001 to a low of 2.2 cases per 100000 population in 2005, representing a 931.8\% decline $(\mathrm{p}<0.001$; figure 1$)$.

\section{Gender}

Our study cohort consists of $779(93.1 \%)$ male and 58 $(6.9 \%)$ female patients. The overall incidence rate was significantly higher among men compared with women; 12.1 cases (95\% CI 11.3 to 13.0 ) vs 0.9 (95\% CI 0.7 to1.1) cases per 100000 population per year, respectively $(\mathrm{RR}=13.4, \mathrm{p}<0.001)$.

Among men, the incidence rate declined significantly from 39.4 cases per 100000 population in 2002 to 3.8 cases per 100000 population in $2005(\mathrm{p}<0.001)$. After 2005, the rates ranged between 4.3 and 7.8, excluding a one-time increase to 12.2 cases per 100000 population in 2007. Among women, a 12-fold decline in the incidence rate was reported, from 2.4 cases in 2001 to 0.2 cases in 2007 per 100000 population $(\mathrm{p}<0.001)$. Since 2008, the incidence began to rise, culminating in 1.4 cases per 100000 population in 2015 .

The male-to-female incidence ratio increased to a peak of 54.1 in 2007 , followed by a steep decline to 9.4 in 2008. Between 2009 and 2015, male-to-female ratio ranged between 5.7 and 15.1.

\section{Age}

The mean age of patients was $30.4 \pm 10.3$ years, and the median age was 27.5 (range 6 months to 79.1 years). No significant difference was noted between female (30.1 \pm 12.3 years $)$ and male ( $30.4 \pm 10.1$ years $)$ patients $(\mathrm{p}=0.857)$.

The incidence of gonorrhoea in the age group of 25-34 years was both the highest and showed the greatest decrease (from 70.6 cases in 2001 to 7.2 cases in

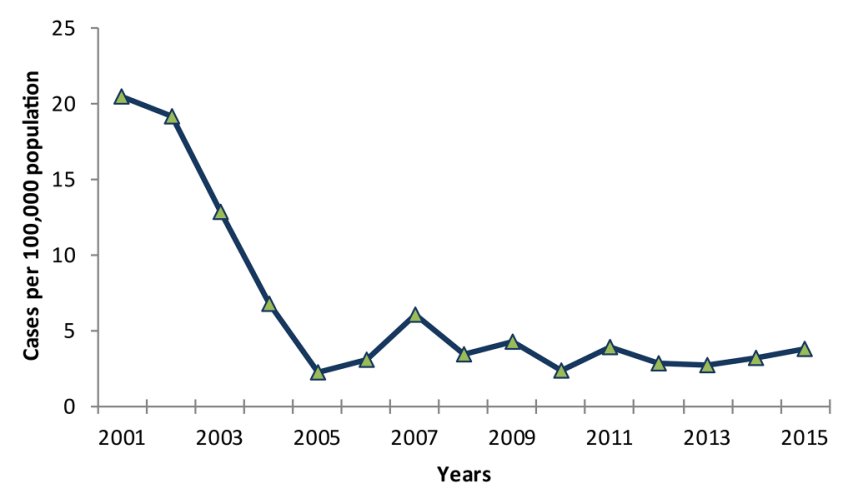

Figure 1 Incidence of gonorrhoea, notified cases in Haifa District, 2001-2015.
2005 per 100000 population, showing a 10-fold drop, $\mathrm{p}<0.001)$. A substantial decrease was also seen in the age group of 35-44 years (from 24.1 cases in 2001 to 3 cases in 2005, representing an eightfold decrease, $\mathrm{p}<0.001$; figure 2).

\section{Ethnicity}

The total number of cases in Jews was $742(88.6 \%)$ and in Arabs was 95 (11.4\%), corresponding to an overall incidence rate of 7.5 (95\% CI 7.0 to 8.1$)$ and $3.0(95 \%$ CI 2.4 to 3.6) per 100000 population per year, respectively $(p<0.001)$. The incidence rate decreased consistently among Jews, falling from 22.8 cases in 2001 to 2.5 cases in 2015 per 100000 population $(\mathrm{p}<0.001)$. Among the Arab population, the rate fell dramatically from a peak of 14.1 cases per 100000 population in 2001 to an absence of case notifications in 2014 ( $p<0.001$; figure 3).

\section{Repeat infection with gonorrhoea}

During a passive follow-up period ranging from 3 months to 15 years, contributing 7765.8 person-years, $11(1.3 \%)$ recurrent episodes of infection with gonorrhoea were registered in our study cohort, occurring in nine different patients. The mean age of patients who suffered from repeat episodes was 23.1 \pm 4.6 years, and the median was 21 (range 19-32) years. All of them were men of Jewish ancestry.

For patients who had at least one repeat infection during the study period, the average time to first repeat infection was $3.7 \pm 3.2$ years.

\section{HIV co-infection}

When the registries of HIV and gonorrhoea in Haifa District were cross-linked, we identified four patients (500 cases per 100000 population) who tested positive for gonorrhoea and HIV. This proportion is significantly higher than HIV positivity in the general population of Haifa (88.1 cases per 100000 population; $\mathrm{p}<0.001$ ).

\section{Seasonal epidemiology}

The seasonal incidence of gonorrhoea is illustrated in figure 4 . The average monthly incidence rates varied from a low of 0.4 cases per 100000 population in September to a high of 0.9 cases per 100000 population in January. The difference in the seasonal incidence rates for winter (3.8 cases per 100000 population) and summer (2.6 cases per 100000 population) was statistically significant $(\mathrm{p}<0.001)$.

\section{DISCUSSION}

From the beginning of the previous decade until 2005, a marked decline in the incidence of gonorrhoea was observed in Haifa District $\left(\mathrm{p}_{\text {trend }}=0.014\right.$ ), followed by a constant rate until the end of follow-up in 2015 $\left(\mathrm{p}_{\text {trend }}=0.590\right)$. 
Figure 2 Incidence of gonorrhoea by age group, notified cases in Haifa District, 2001-2015.

Figure 3 Incidence of gonorrhoea by ethnicity, notified cases in Haifa District, 2001-2015.

Figure 4 Monthly incidences of gonorrhoea, notified cases in Haifa District, 2001-2015. $\neg 15-24$ years old -25 -34 years old -35 -44 years old

$\leftarrow$ 45-54 years old $\longleftarrow$ 55-64
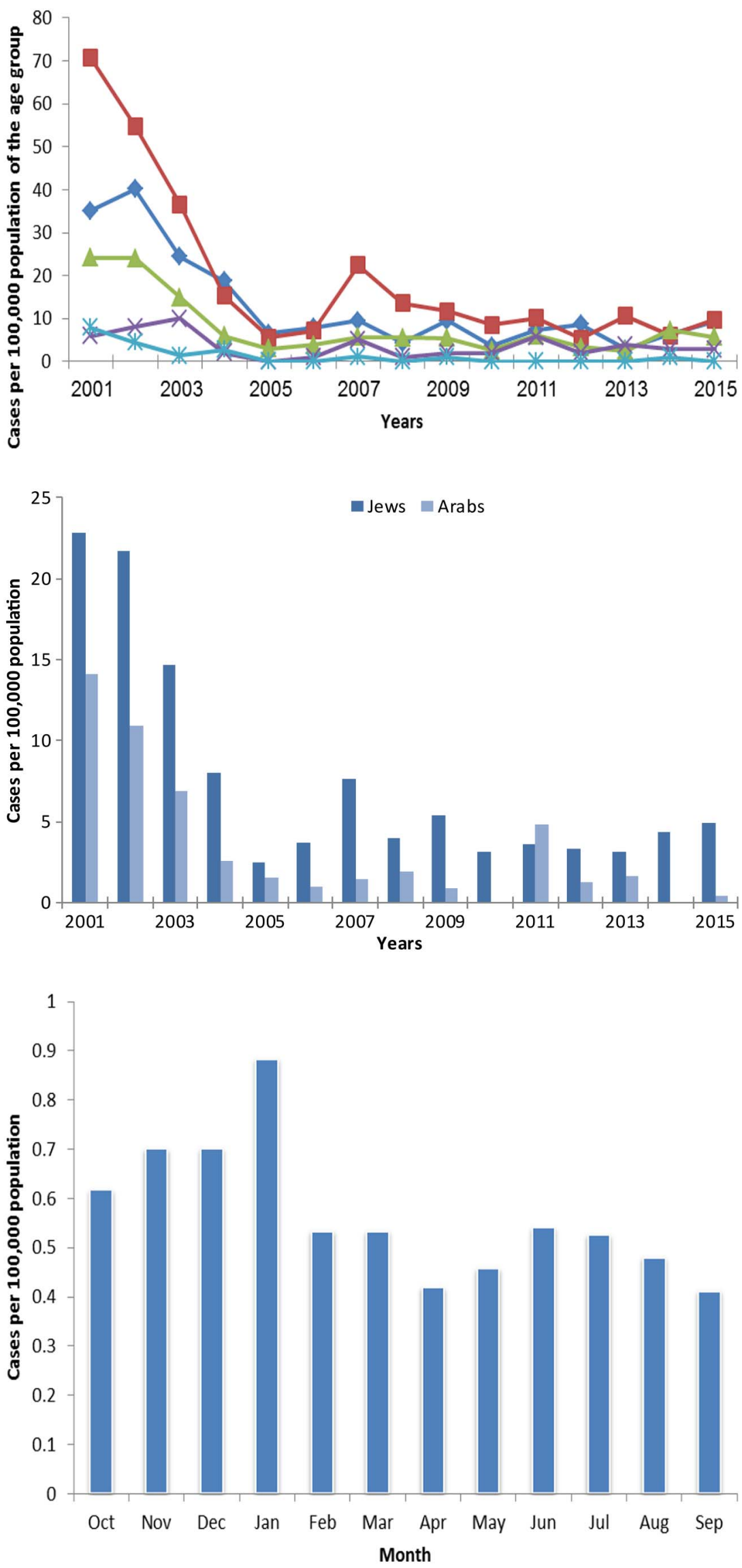


\section{Explanations for the trends}

The consistent drop in the incidence of gonorrhoea since the late 1980s in Israel was attributed mainly to the worldwide HIV epidemic. It is assumed that widespread fear of HIV infection led to less hazardous sexual practices, especially among MSM, and to an overall decline in all STDs. ${ }^{11}$ Although evidence for sexual behaviour risk reduction in response to the HIV epidemic among heterosexuals is limited, increased condom use has been documented. ${ }^{12}$ This decline was not exclusive for Israel; it was also observed in Europe and the USA and was reinforced by researches demonstrating an association between the rise in prevalence of anti-HIV antibodies in homosexual and bisexual men and a decline in the frequency of gonorrhoea. ${ }^{2}{ }^{13}$ Interestingly, this decrease is valid also for early syphilis in Haifa District (Grifat R, unpublished data).

A rise in gonorrhoea incidence was reported in the general Israeli population during the years 1999-2002, and paralleled the increasing rates in the UK and several other European countries. ${ }^{14-18}$ Subsequent to this surge, some interventions were adopted by the Israeli Ministry of Health in order to control the disease's occurrence. Health education and prevention programmes were intensified, and free medical check-up for commercial sex workers were initiated. Furthermore, free outpatient and mobile STD clinics have been made accessible to the public. These interventions may have contributed to the observed decline in gonorrhoea. ${ }^{19}$

In the USA, an ongoing decline since the 1970s can be explained by the shift in the age distribution of the US population towards increased ages, indicating that a decreasing proportion of people belong to the highest risk age groups. ${ }^{20}$ This explanation is far from being relevant in Israel due to increasing birth rates and an increasing proportion of younger people within the general population.

\section{Gender and ethnic distribution of patients}

Reported incidence rates of gonorrhoea had historically been higher in men than in women, a discrepancy ascribed mainly to the higher rate of asymptomatic disease in women and higher incidence of infection among MSM. In the USA, increased active case finding among women and the decline in the occurrence among MSM since the 1980s have resulted in a nearly equal proportion of cases in men and women nationally. ${ }^{21}$ However, the incidence rate in our study was 134-fold higher among men compared with women. The male-to-female ratio fluctuated but generally trended downwards until it reached an all-time low in 2015 (4.5:1). The main explanation for the male predominance in relation to reports from other western countries is the lack of screening programmes for gonorrhoea among pregnant women, which might lead to underdiagnosis of the infection among women. Furthermore, according to local social norms, it is more acceptable for men to have multiple sexual partners, while it is less acceptable for women.

Risk factors for gonococcal infections include belonging to a minority ethnic group, having a low educational level, and being from a low socioeconomic level. ${ }^{10} 2223$ However, the risk of infection with gonorrhoea in Arabs, who constitute the minority disadvantaged ethnic population in Israel, was 2.5-fold lower than in Jews. The main explanation of this finding is the unsafe sexual practice among Jews who adopt a more western and liberal lifestyle as compared with conservative norms in the Arab society. Many polls, articles and surveys suggest that Israeli-Arabs as a group are generally conservative, traditional and hierarchical with regard to sex roles, the centrality of the family and sociocultural hierarchy. ${ }^{24}$ Another potential interpretation of the discrepancy, although less probable, is the lower testing rate among Arab patients due to lower health awareness. This interpretation is less probable because the two populations share the same healthcare facilities and are exposed to similar primary prevention campaigns.

\section{HIV co-infection}

Gonorrhoea has a significant epidemiological association with HIV. First, the acquisition of gonococcal infection indicates risky sexual practice that is, in turn, an identified predictor for HIV infection. Second, gonococcal infections seem to facilitate both the transmission and acquisition of $\mathrm{HIV}^{3}{ }^{4}$ and conversely, the presence of HIV infection is associated with increased acquisition of $N$. gonorrhoeae. ${ }^{25}$ The concentrations of HIV RNA in semen were eightfold higher among patients with gonococcal urethritis as compared with controls. ${ }^{3}$ Moreover, treatment of the urethritis lowered HIV RNA levels by two-thirds. The molecular mechanisms accounting for the enhanced HIV transmission may include activation of HIV-infected CD4 cells by $N$. gonorrhoeae, causing increased HIV expression and viral production. ${ }^{26}$ Furthermore, gonococcal infection during the acquisition of HIV is associated with an altered HIV-specific CD8 cell response. ${ }^{27}$ In our study, we found that the prevalence of HIV among patients with gonorrhoea (500.0 per 100000 ) was significantly higher than in the general population (88.1 per $100000 ; \mathrm{p}<0.001$ ).

\section{Seasonality}

Israel is located between $29^{\circ}$ and $33^{\circ}$ north of the equator and is characterised as a subtropical region. The northern and coastal regions of Israel have a Mediterranean climate, characterised by hot and dry summers with cool, rainy winters. Israel generally has two main seasons-winter (October to March) and summer (April to September).

Our data depict that gonococcal infections are more prevalent in the winter. This observation is in contrast to previous reports on the seasonality of gonorrhoea ${ }^{19} 2829$ and other STDs, ${ }^{29}{ }^{30}$ which illustrate a higher frequency in summer. Our results are in line with the findings of 
numerous studies demonstrating higher levels of testosterone in the fall months. ${ }^{31-33}$

Our reporting system may suffer from a delay that can potentially interfere with the seasonal analysis. However, it is less probable that such a delay would affect data collected over an extended period of 15 years.

\section{Limitations of the study}

In addition to the retrospective design of the study, we provide data from a relatively small region populated with no more than one million inhabitants, which may limit the generalisability of the results. Second, we could not elucidate the precise way of transmission and the sexual orientation of the infected patients, thus reducing the possibility of focusing on the exact causes and target populations. Furthermore, we could not examine trends of the infection among MSM, which were associated with the majority of outbreaks of the infection in industrialised countries. $^{34-37}$

\section{CONCLUSION}

This population-based study demonstrates that the incidence rate of gonorrhoea infection decreased dramatically from 2001 to 2005, with no substantial subsequent fluctuations. People of Jewish ancestry were significantly more affected by the infection than were Arabs, which may be attributed to less safe sexual practices. An overwhelming male predominance of infection was observed. The infection was more frequent in winter and was significantly more prevalent among patients with coexisting HIV infection.

\author{
Author affiliations \\ ${ }^{1}$ Department of Dermatology, Rambam Health Care Campus, Haifa, Israel \\ ${ }^{2}$ Rappaport Faculty of Medicine, Technion-Israel Institute of Technology, Haifa, \\ Israel \\ ${ }^{3}$ Haifa District Office, Ministry of Health, Haifa, Israel \\ ${ }^{4}$ Diabetes and Metabolism and Internal Medicine D, Institute of \\ Endocrinology, Rambam Health Care Campus, Haifa, Israel
}

Contributors KK and RG had full access to all of the data in the study and take responsibility for the integrity of the data and the accuracy of the data analysis. KK and MK were involved in study concept and design, and acquisition, analysis and interpretation of data. KK and RG were involved in drafting of the manuscript and critical revision of the manuscript for important intellectual content. MK was involved in statistical analysis. RG was involved in administrative, technical and material support. MK and RG were involved in study supervision.

Funding This research received no specific grant from any funding agency in the public, commercial or not-for-profit sectors.

Competing interests None declared.

Patient consent Obtained.

Ethics approval The Institutional Ethics Committee of Department of Epidemiology, Haifa District.

Provenance and peer review Not commissioned; externally peer reviewed.

Data sharing statement No additional data are available.

Open Access This is an Open Access article distributed in accordance with the Creative Commons Attribution Non Commercial (CC BY-NC 4.0) license, which permits others to distribute, remix, adapt, build upon this work non-commercially, and license their derivative works on different terms, provided the original work is properly cited and the use is non-commercial. See: http://creativecommons.org/licenses/by-nc/4.0/

\section{REFERENCES}

1. World Health Organization. Global incidence and prevalence of selected curable sexually transmitted infections. World Health Organization. 2008. http://www.who.int/reproductivehealth/ publications/rtis/2008_STI_estimates.pdf (accessed 17 Dec 2012).

2. Ministry of health, State of Israel. Notifiable infectious disease in Israel: 60 years of surveillance, 1951-2010. 2010. http://www.health. gov.il/publicationsfiles/disease1951_2010.pdf

3. Cohen MS, Hoffman IF, Royce RA, et al. Reduction of concentration of HIV-1 in semen after treatment of urethritis: implications for prevention of sexual transmission of HIV-1. AIDSCAP Malawi Research Group. Lancet 1997;349:1868.

4. Braunstein SL, Ingabire CM, Kestelyn E, , et al. High human immunodeficiency virus incidence in a cohort of Rwandan female sex workers. Sex Transm Dis 2011;38:385-94.

5. Laga M, Manoka A, Kivuvu M, et al. Non-ulcerative sexually transmitted diseases as risk factors for HIV-1 transmission in women: results from a cohort study. AIDS 1993;7:95-102.

6. Sullivan $A B$, Gesink DC, Brown $P$, et al. Are neighborhood sociocultural factors influencing the spatial pattern of gonorrhea in North Carolina? Ann Epidemiol 2011;21:245-52.

7. Health Protection Agency (HPA). Sexually transmitted infections in men who have sex with men in the UK: 2011 report. London: HPA, 2011. http://www.hpa.org.uk/webc/HPAwebFile/HPAweb_C/ 1317131685989

8. Trienekens SC, Koedijk FD, van den Broek IV, et al. Sexually transmitted infections, including HIV in the Netherlands in 2011. Bilthoven: National Institute for Public Health and the Environment (RIVM), 2012. RIVM r

9. Norwegian Institute of Public Health. Gonoré og syfilis i Norge 2011 [Gonorrhoea and syphilis in Norway, 2011]. Oslo: Norwegian Institute of Public Health. Norwegian. (accessed 30 Jun 2012). http:// www.fhi.no/eway/default.aspx?pid=233\&tr

10. Klausner JD, Barrett DC, Dithmer D, et al. Risk factors for repeated gonococcal infections: San Francisco, 1990-1992. J Infect Dis 1998;177:1766-9.

11. Gellan MC, Ison CA. Declining incidence of gonorrhoea in London a response to fear of AIDS? Lancet 1986;2:920.

12. Yagupsky $\mathrm{P}$, Schahar $\mathrm{A}$, Peled N, et al. Increasing incidence of gonorrhea in Israel associated with countrywide dissemination of a ciprofloxacin-resistant strain. Eur J Clin Microbiol Infect Dis 2002;21:368-72.

13. Carne CA, Weller IV, Johnson AM, et al. Prevalence of antibodies to human immunodeficiency virus, gonorrhoea rates, and changed sexual behaviour in homosexual men in London. Lancet 1987:329:656-8.

14. Hughes G, Andrews N, Catchpole M, et al. Investigation of the increased incidence of gonorrhoea diagnosed in genitourinary medicine clinics in England, 1994-6. Sex Transm Infect 2000;76:18-24.

15. Fennema JS, Cairo I, Coutinho RA. [Substantial increase in gonorrhea and syphilis among clients of Amsterdam Sexually Transmitted Diseases Clinic]. Nederlands Tijdschrift Voor Geneeskunde 2000;144:602-3.

16. Green MS, Anis E, Gandacu D, et al. The fall and rise of gonorrhoea incidence in Israel: an international phenomenon? Sex Transm Infect 2003;79:116-18.

17. Page-Shafer K, McFarland W, Kohn R, et al. Increases in unsafe sex and rectal gonorrhea among men who have sex with menSan Francisco, California, 1994-1997. MMWR Morb Mortal Wkly Rep 1999;48:45-8.

18. Berglund $\mathrm{T}$, Unemo $\mathrm{M}$, Olcén $\mathrm{P}$, et al. One year of Neisseria gonorrhoeae isolates in Sweden: the prevalence study of antibiotic susceptibility shows relation to the geographic area of exposure. Int J STD AIDS 2002;13:109-114.

19. Mimouni D, Bar-Zeev $\mathrm{Y}$, Davidovitch N, et al. Secular trends of gonorrhea in young adults in Israel: three decades of follow-up. Eur J Clin Microbiol Infect Dis 2010;29:1111-15

20. Fox KK, Whittington WL, Levine WC, et al. Gonorrhea in the United States, 1981-1996. Demographic and geographic trends. Sex Transm Dis 1998;25:386-93.

21. Centers for Disease Control and Prevention. Sexually transmitted disease surveillance, 2012. Atlanta, GA: U.S. Department of Health and Human Services, 2013. 
22. Currie MJ, Martin SJ, Soo TM, et al. Screening for chlamydia and gonorrhoea in men who have sex with men in clinical and non-clinical settings. Sex Health 2006;3:123-6.

23. Mertz KJ, Levine WC, Mosure DJ, et al. Screening women for gonorrhea: demographic screening criteria for general clinical use. Am J Public Health 1997;87:1535-8.

24. Haj-Yahia MM. Beliefs about wife beating among Arab men from Israel: the influence of their patriarchal ideology. J Fam Violence 2003;4:533-58.

25. McClelland RS, Lavreys L, Katingima C, et al. Contribution of HIV-1 infection to acquisition of sexually transmitted disease: a 10-year prospective study. J Infect Dis 2005;191:333-8.

26. Malott RJ, Keller BO, Gaudet RG, et al. Neisseria gonorrhoeae-derived heptose elicits an innate immune response and drives HIV-1 expression. Proc Natl Acad Sci USA2013;110:10234-9.

27. Sheung A, Rebbapragada A, Shin LY, et al. Mucosal Neisseria gonorrhoeae coinfection during HIV acquisition is associated with enhanced systemic HIV-specific CD8 T-cell responses. AIDS 2008;22:1729-37.

28. Schroeder B, Tetlow P, Sanfilippo JS, et al. Is there a seasonal variation in gonorrhea and chlamydia in adolescents? $\mathrm{J}$ Pediatr Adolesc Gynecol 2001:14:25-7.

29. Ross JDC, Scott GR. Seasonal variation in gonorrhoea. Eur J Epidemiol 1992;8:252-5.
30. Damiba AE, Vermund SH, Kelley KF. Rising trend of reported gonorrhoea and urethritis incidence in Burkina Faso from 1978 to 1983. Trans R Soc Trop Med Hyg 1990;84:132-5.

31. Dabbs JM Jr. Age and seasonal variation in serum testosterone concentration among men. Chronobiol Int 1990;7:245-9.

32. Svartberg J, Jorde R, Sundsfjord J, et al. Seasonal variation of testosterone and waist to hip ratio in men: the Troms study. $J$ Clin Endocrinol Metab 2003;88:3099-104.

33. Smith RP, Coward RM, Kovac JR, et al. The evidence for seasonal variations of testosterone in men. Maturitas 2013;74: 208-12.

34. Satterwhite CL, Joesoef MR, Datta SD, et al. Estimates of Chlamydia trachomatis infections among men: United States. Sex Transm Dis 2008;35:S3-7.

35. Peterman TA, Tian LH, Metcalf CA, et al. High incidence of new sexually transmitted infections in the year following a sexually transmitted infection: a case for rescreening. Ann Intern Med 2006;145:564-72.

36. Sanders EJ, Thiong'o AN, Okuku HS, et al. High prevalence of Chlamydia trachomatis and Neisseria gonorrhoeae infections among HIV-1 negative men who have sex with men in coastal Kenya. Sex Transm Infect 2010;86:440-1.

37. Cook RL, St George K, Silvestre AJ, et al. Prevalence of chlamydia and gonorrhoea among a population of men who have sex with men. Sex Transm Infect 2002;78:190-3. 